Journal of Management,

\title{
APPLICATION OF ARIMA MODEL FOR FORECASTING OF ROOM RESERVATION IN HOTELS *
}

DOI: 10.17261/Pressacademia.2015414466

Celal Hakan Kagnicioglu', Mune Mogol'

'Anadolu University. chkagnic@anadolu.edu.tr

${ }^{2}$ Anadolu University. mmogol@anadolu.edu.tr

\section{Keywords}

Tourism, hotel, forecasting, ARIMA, Box-Jenkins

\begin{abstract}
Accomodation is the main area of tourism industry. In order to determine man, machine and material reguirement, right material must be on the right place on the right time. Man and material requirements are depend on room demand. Main aim of this study is to forecast hotel room demand for a five stars and international chain hotel that has been established in Ankara. In order to forecast the room demand, ARIMA, one of the most popular advanced Box-Jenkins Model, has been used. The reason of selecting this model is the consideration of time series with probabilistic and stochastic characteristics by ARIMA and performance of it for forecasts in short time periods. While analyzing, it is seen that the serie has no trend and seasonal effect but has a autocorelation. After analyses on first order differentiated data ARIMA $(2,1,1)$ model has been found. Test statistics for models with $\% 95$ confidence interval are; $A R(1)$ for $p=0, A R(2)$ for $p=0.01$ ve $M A(1)$ for $p=0$. The validity of the model, ARIMA $(2,1,1)$ has been evaluated by Akaike Information Criterion (AIC). StatGraphics 16.2 and Eviews 8 has been used for analyses. After determining model, model parameters has been coded in $\mathrm{C} \#$. The coded model has been used as an input in a decision support system which has been used for material reguirement planning for a hotel and stored in a model base. Main role of this model is to determine master production scheduling for hotel room demand forecast in decision support system.
\end{abstract}

JEL Classification C32, L80, M11

\section{OTELLERDE ODA TALEBININ ÖNGÖRÜLMESINDE ARIMA MODELI UYGULAMASI}

Anahtar Kelimeler

ARIMA, Box-Jenkins.
Turizm, otel, öngörü,

\section{ÖZET}

Turizm endüstrisinin önemli faaliyet alanlarından biri konaklamadır. $\mathrm{Bu}$ faaliyetlerin aksamadan yürütülmesi, gerekli malzeme, ekipman ve işgücünün doğru yer ve zamanda olması gerekmektedir. Malzeme ve işgücünün belirlenmesinde ise oda talebinin önceden bilinmesi önemlidir. Beş yıldızlı otellerin oda talebinin öngörülmesi amacıyla yapılan bu çalışma, Ankara' da beş yıldızlı, uluslar arası, zincir bir şehir oteli geçmiş satış verilerinden yararlanılarak gerçekleştirilmiştir. Çalışmada öngörü modeli olarak Box-Jenkins modellerinden biri olan ARIMA modeli seçilmiştir. Bu modelin seçilmesinde ARIMA'nın zaman serilerinin olasılıklı ve rassal özelliklerini dikkate alması ve kısa dönemdeki tahminlemedeki başarısı etkili olmuştur. Yapılan analizlerde serinin bir trend ve mevsimsellik barındırmamasına karşın otokorelasyonlu bir yapıya sahip olduğu görülmüştür. Bu durum otokorelasyon ve kısmı otokorelasyon grafiklerinde gözlenmiştir. Durağan verilerle çalışılması gerekmesi nedeniyle serinin birinci derece farkı alınmıştır. Durağan veri üzerinde gerçekleştirilen analizler sonucu ARIMA $(2,1,1)$ modeline ulaşılmıştır. Modele ait test istatistikleri \%95 güven aralı̆ı̆nda; $A R(1)$ için $p=0, A R(2)$ için $p=0.01$ ve $M A(1)$ için $p=0$ 'dır. Modelin uygunluğuna AIC (Akaike Information Criterion) kriterine göre karar verilmiştir. Analizlerde StatGraphics 16.2 ve Eviews 8 kullanılmıştır. Parametreleri belirlenmiş model C \#' ta kodlanmıştır. Bu kodlar, otellerin malzeme ihtiyaç planlamasını yapan bir karar destek sistemine girdi oluşturmakta; model tabanında yer almaktadır. Bu model, karar destek sisteminde oda talebi için ana hizmet çizelgesinin oluşturulmasında kullanılmaktadır.

JEL Sınıflandırması C32, $L 80$ ve $M 1$ dolu University under Scientific Research Projects (Project number: 1307E288). 


\section{GiRiş}

Turizm sektörü her geçen gün büyümekte ve turizm gelirleri her geçen gün artmaktadır. Uluslararası Dünya Turizm Örgütü (UNWTO) 2014 verilerine göre turizm gelirleri 1 trilyon 245 milyar dolara yükseldi (UWTO, 2014). Bu rakam bir önceki yıla göre \%3,7 artış anlamına gelmektedir. Gelirlerin bu artışı karşısında yeni açılan işletme sayısı da katlanarak çoğalmaktadır.

Her yıl artış gösteren bu rakamlar karşısında doğru bir planlama yapmak ve daha gerçekçi rakamlarla öngörüde bulunmak kaçınılmazdır. Ayrıca, turizm endüstrisinin ürünlerinin stoklanamaması durumu da göz önünde bulundurulduğunda öngörülerde kesinlik oranı önem kazanmaktadır (Witt ve Witt, 1995).

En temel turizm gelirlerinden biri konaklama gelirleridir. Bu nedenle işletmeler, oda talebini önceden tespit etmek ve buna yönelik yatırım vb. planlamalar yapmak istemektedirler.

Bu çalışma beş yıldızı otellerin oda talebinin öngörülmesi amacıyla yapılmış ve modelin kurulmasında Ankara' da beş yıldızlı, uluslararası, zincir bir şehir oteli geçmiş satış verilerinden yararlanılmıştır. Çalışmada öngörü modeli olarak Box-Jenkins modellerinden biri olan ARIMA modeli seçilmiştir. Yapılan denemeler sonucu ARIMA $(2,1,1)$ modeli en iyi performansı veren model olarak belirlenmiştir. Geliştirilen bu model ile, otel işletmelerinin malzeme ihtiyaç planlamasını yapan bir karar destek sistemine girdi oluşturulmuştur.

Geliştirilen KDS, beş yıldızlı otellerin temizlik sürecine girdi oluşturan temizlik kimyasalları için MiP yapmaktadır. Model tabanında geliştirilen öngörü sistemi, haftalık rezervasyon tahminlerini yapmaktadır. Her bir oda için kullanılan malzemelere ilişkin ürün ağaçları oluşturulup, sisteme tanıtımı yapıldıktan sonra KDS, tahmini rezervasyonlara göre toplam malzeme ihtiyacını belirlemektedir. Stok düşüşlerinin ve sarfiyatlarının otomatik hesaplanabildiği bu KDS' de toplam beş modül yer almaktadır. Bu modüller; Yönetim, İşlemler, Raporlar, Tanımlamalar, Çamaşırhane ve Kullanıcı'dır. ARIMA modeli bunlardan Yönetim modülü altında tahmini rerzervasyonların oluşturulmasında yer almaktadır.

\section{LITERATÜR}

Otel oda talebinin belirlenmesinde pek çok yöntem kullanılmaktadır. Rajopadhye, Ghalia, Wang, Baker ve Eister (2001) çalışmalarında Holt-Winters'ın Modelini kullanarak öngörüde bulunmuşlardır.

Dharmaratne (1988) Barbados'ta turist varışları için yaptığı çalışmada ARIMA $(2,1,1)$ modellerini geliştirmiş ve test etmiştir. Model için StatGraphics (1988) kullanmıştır. Model 1956-87 ve 1956-1991 yılları verilerine göre geliştirilmiştir. 1956-87 yılları verileri kullanılarak geliştirilen model 1988-1992 yılları turist varışlarını öngörmede kullanılmıştır. 1956-1991 yılları verileri kullanılarak geliştirilen model 1992-1993 yıllarının turist varışlarının öngörülmesinde kullanılmıştır.

Lim ve McAleer (2002) Avusturalya' ya Hong Kong, Malezya ve Singapur'dan gelen turist sayılarını belirlemek için ARIMA modellerinden yararlanmışlardır. Mevsimsel ve mevsimsel olmayan iki model geliştirmişlerdir. Mevsimsel olmayan model diğerine göre daha iyi sonuç üretmektedir. Bu modelle 1990-1996 arasındaki ülkeye gelen turist sayılarını öngörmüşlerdir. 
Lim ve Pan (2005) çalışmalarında Çin'deki iç turizm talebini öngörmede ARIMA modelinden yararlanmışlardır. Bunun için 1986-2000 yılları arasındaki verilerden yararlanmışlardır.

Preez ve Witt (2003) çalışmalarında uluslararası turizm talebini öngörmüşlerdir. Geliştirdikleri modeller arasında en iyi performansı ARIMA modeli göstermiştir.

Witt ve Witt (1995)'in çalışmalarında turizm öngörüsü alanında yapılmış ampirik çalışmaları incelemişlerdir. Çalışmalarında diğer modellere göre otoregresif model kurulumunun daha az çabayla mümkün olacağı ve modelin iki yıllık süreçler için diğer modellere oranla daha iyi sonuç vereceği ifade edilmiştir.

Chu (1998) yaptığı çalışma için geliştirdiği mevsimsel ARIMA modelini kullanarak 10 Pasifik Asya ülkesi için turist gelişlerini öngörmüştür. Chen, Bloomfield ve Cubbage (2007) çalışmalarında 8 öngörü yöntemiyle Amerikan Ulusal Parkı'nın ziyaretçi talebini öngörmüşlerdir. Chen vd. (2007) çalışmalarında geliştirdikleri 3 model arasında hata yüzdesi değerine göre en iyi ikinci sonucu veren modelin ARIMA olduğunu belirlemişlerdir. Chen ve Wang (2007) çalışmalarında Çin'e 1985-2001 yılları arasında gelen turist sayıları kullanılarak turizm talebini öngörmüşlerdir. Bunun için regresyondan (Support Vector Regression,SVR) yararlanmışlardır. SVR'nin performansını ise yapay sinir ağları ve ARIMA ile ölçmüşlerdir. SVR, ARIMA' ya göre daha iyi sonuçlar üretmiştir. Bu yöntemler arasında MAPE değerlerine göre ARIMA en iyi sonucu üretmiştir.

Burger, Dohnal, Kathrada ve Law (2001) çalışmalarında ARIMA ile birlikte pek çok zaman serisi öngörü modelini kullanarak, 1992-1998 yılları arasındaki verilerinden yararlanarak, Amerika'dan Güney Afrika'daki Durban'a olan turist talebini belirlemişlerdir. Çalışma geliştirilen modellerden 14 tanesi içinde MAPE değerleri en düşük olan modeller yapay sinir ağları modelleridir. ARIMA modelleri ise 5. 6. ve 7. sırada en düşük MAPE değerini üretmiştir.

Cho (2001) geliştirdiği ARIMA modelinin diğer iki modele göre daha iyi sonuç verdiğini ortaya koymuştur. Cho (2003) ARIMA ve 3 ayrı model kullanarak, Amerika, İngiltere, Japonya, Singapur, Kore ve Tayvan için turist sayısını öngörmek istemişlerdir. Geliştirilen modeller arasında ARIMA modeli Japonya ve Kore turist talebini öngörmede yeterli bir model olarak belirlenmiştir.

Chu (2009)' nun geliştirdiği modeller arasında en iyi performansı ARIMA modeli göstermiştir. Chu Asya ülkelerindeki turizm talebini bu model aracıllğıyla öngörmüştür.

Kulendran ve Shan (2002) Çin iç turizm talebini belirlemede 4 çeşit ARIMA modeli geliştirmiş, içlerinden en iyi sonuç veren modeli uygulamışlardır.

Kulendran ve Witt (2003) İngiltere'den 6 farklı popüler destinasyona olan turist talebini belirledikleri çalışmalarında ARIMA modelini de kullanmışlardır. Kısa dönemde zaman serileri modellerinin diğer modellere üstün geldiği sonucuna ulaşılmıştır.

Goh ve Law (2002) geliştirdikleri ARIMA modeliyle Hong Kong iç turizmi için öngörüde bulunmuşlardır. Geliştirdikleri model mevsimsel ARIMA modelidir. 
Song, Witt ve Jensen (2003) Danimarka'nın iç turizm değerini öngörebilmek için 6 ekonometrik model kurmuşlardır. Bu modellerden biri ARIMA'dır. Yıllık verilerle çalışılmış olup; 1, 2, 3 ve 4 yıllık ayrı ayrı her bir modelle öngörüde bulunmuşlardır.

Wong, Song, Witt, Wu(2007) çalışmalarında ARIMA ile birlikte üç metotla Hong Kong'a 10 farklı destinasyondan gelen turist sayılarını öngörmüşlerdir. Yüksel (2007) ARIMA ile birlikte 5 farklı modelleme aracıyla Ankara'daki beş yıldızı bir otelde 149 adet aylık veriyle uygun öngörü aracını belirlemiştir. En iyi öngörü aracı Winters'ın mevsimsel modeli olmuştur.

Yapılan çalışmalar incelendiğinde ARIMA modelinin turizm öngörülerinde sıklıkla tercih edildiği görülmüştür.

\section{YÖNTEM}

Zaman serileri, bir dönemden diğerine değişkenlerin değerlerinin ardışık bir şekilde gözlendiği sayısal büyüklüklerdir. Geleneksel zaman serilerine farklı yaklaşımlar ise BoxJenkins tarafından geliştirilmiştir. (Sevüktekin ve Nargeleçekenler, 2010: 41).

$\operatorname{ARIMA}(p, d, q)(P, D, Q)$ modeli, doğrusal otoregresif modeller $(A R)$ ve hareketli ortalama modellerinin (MA) kombinasyonu olarak bilinen Box-Jenkins Modellerinin en çok bilinenidir (Montgomery, vd., 2008: 230; Box vd., 2008: 12). Box-Jenkins (1970) tarafından geliştirildiği için çoğu kez Box-Jenkins modeli olarak bilinmektedir (Chatfield, 2001: 120).

ARIMA $(p, d, q)$ modelindeki $p$ : doğrusal otoregresif modelin derecesini, $d$ : fark alma derecesini, q: hareketli ortalama modelinin derecesini ifade etmektedir (Sevüktekin vd., 2010: 238).

Yule (1927) her serinin stokastik bir karakterinin olduğunu söylemesinin ardından Slutsky, Walker, Yaglom ve Yule tarafından otoregresif AR ve MA modelleri geliştirilmiştir. ARIMA ise AR ve MA modellerinin geliştirilmiş bir şeklidir (Gooijer ve Hyndman, 2006).

ARIMA, klasik tek değişkenli zaman serisi öngörü araçlarından, sadece denklem veya model oluşturulması yönüyle değil, zaman serilerinin olasılıklı veya rassal özelliklerini dikkate alarak, modelleme yapması ve kısa dönem öngörüdeki başarısı yönüyle diğerlerinden ayrılmaktadır (Nahmias, 2009: 95).

Otel işletmelerinin oda talebi rassal bir yapı gösterdiği için ARIMA modelinin talep planlamada bu işletmeler için uygun bir araç olduğu düşünülmektedir.

Zaman serisi modellemelerinde yapılması gereken işlemlerin en başında, veriye ait dört temel bileşeninden ayrıştırılması gerekmektedir. Bu bileşenler; trend, mevsimsellik, düzensiz hareketler ve konjonktürel bileşendir (Sevüktekin vd., 2010: 42).

Diğer önemli bir işlem ise fark alma işlemidir. Bu işlem serinin durağanlaştırılması için yapılmaktadır (Henrik, 2008: 130). Durağan seriler, zaman içinde aynı istatistiki davranışı sergiler ve sabit olasılık dağılımına sahiptirler (Montgomery, 2008: 232).

ARIMA modeline ilişkin işlemler şu şekilde özetlenmektedir (Montgomery vd.,2008: 231; Box vd., 2008: 286; Nahmias, 1999: 94; Makridakis, Hibon, 1979); 
1. Serinin durağan olup olmadığı araştırılmaktadır. Mevsimsellik ve trend bileşeni için oto-korelasyon fonksiyonuna veya kısmi otokorelasyon grafiğine bakılır ve birim kök testleri incelenmektedir.

2. Mevsimsellik özellik gösteriyor ve trend barındırıyorsa bu bileşenlerden arındırılmaktadır.

3. Seri durağan değilse fark alma işlemi yapılmaktadır. Her fark işlemi sonrası serinin durağanlığı, birim kök testi ile sınanmaktadır. Birim kök var ise seri durağan değildir. Seri durağan hale gelene kadar fark alma işlemi yapılmaktadır.

4. Durağan hale gelmiş ve mevsimsellikten arındırılmış veri ile uygun ARIMA $(p, d, q)$ modelinin parametreleri ( $p$ : otoregresif, $d$ : fark alma derecesi, $q$ : hareketli ortalama anlamına gelmektedir) belirlenmektedir.

5. Belirlenen modelin uygunluğu sınanmaktadır.

Çalışmanın izleyen bölümünde bu adımlar izlenerek uygun model geliştirilmiştir.

\section{BULGULAR}

Yapılan gözlem ve görüşmelerle elde edilen satış rakamlarının zaman serisi grafiklerine bakıldığında serinin her hangi bir trend veya mevsimsellik barındırmamasına rağmen, otokorelasyonlu bir kalıp gösterdiği söylenebilir. Grafik 1 bu durumu özetlemektedir.

\section{Grafik 1: Zaman Serisi Grafiği}

Time Series Plot for Gunluk Satis

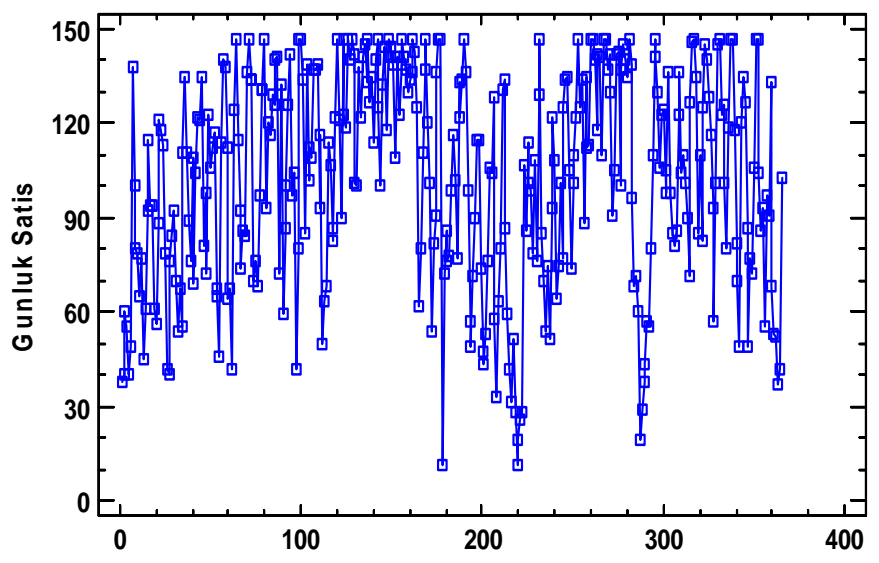


Grafik 1 incelendiğinde serinin ortalamasının değişken bir yapıda olduğu, dolayısıyla durağan olmadığı söylenebilir. Bazı durumlarda seri trend ve mevsimselliğe sahip olmasa da veriler arasında yüksek otokorelasyon gözlenebilmektedir (Sevüktekin, Nargeleçekenler, 2010: 18). Orijinal seride, mevsimsellik ve trend yoktur. Serinin durağanlığı birim kök testiyle incelenmektedir. Birim kök testi de serinin düzeyde (sıfırıncı seviyede) durağan olmadığını göstermektedir. Sonuçlar Tablo 1' de özetlenmektedir.

Tablo 1: Birim Kök Testi Sonuçları

Null Hypothesis: SERIES01 has a unit root

\begin{tabular}{llll}
\hline \hline & & & \\
& & t-Statistic & Prob. $^{*}$ \\
\hline \hline Augmented Dickey-Fuller test statistic & $\underline{-3.001998}$ & $\underline{0.0357}$ \\
\hline Test critical values: & 1\% level & -3.448782 & \\
& $5 \%$ level & -2.869558 \\
& $10 \%$ level & -2.571110 \\
\hline \hline
\end{tabular}

*MacKinnon (1996) one-sided p-values.

Tablo 1 incelendiğinde Augmented Dickey-Fuller test istatistiği ile T istatistiği değerleri kıyaslandığında, \%5 seviyesinde sonuçlar anlamlı kabul edilmektedir. Bu nedenle serinin birim kök barındırdığı ve durağan olmadığına karar verilmektedir. Durum, Grafik 2 ' de gösterilmektedir. 


\section{Grafik 2: Dizinin Otokorelasyon Grafiği}

Estimated Autocorrelations for Gunluk Satis

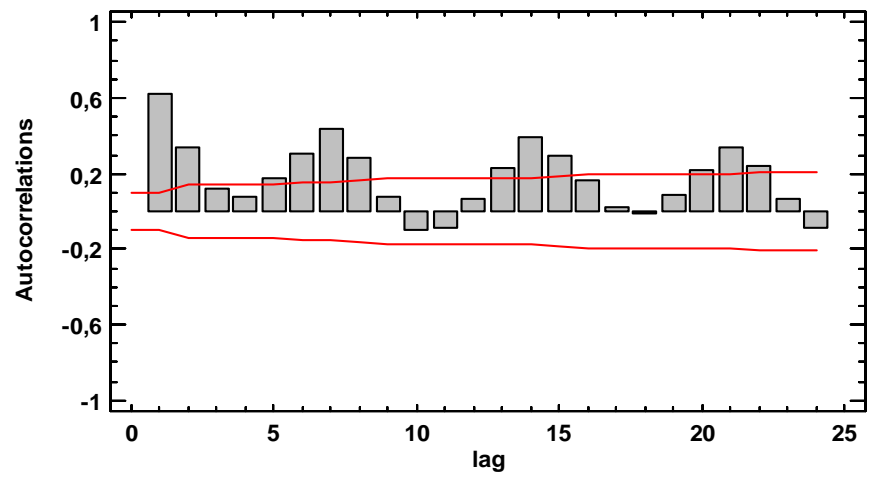

Otokorelasyon grafiği incelendiğinde serinin, konjonktürel bir yapıyı barındırdığı, belli bir gecikmeden sonra otokorelasyonun hızlı bir şekilde düşmediği, başka bir ifade ile anlamlı bir otokorelasyon barındırdığı, dolayısıyla durağan olmadığı söylenmektedir. Serinin kısmi otokorelasyon grafiğinin de incelenmesi gerekmektedir.

\section{Grafik 3: Dizinin Kısmi Otokorelasyon Grafiği}

Estimated Partial Autocorrelations for Gunluk Satis

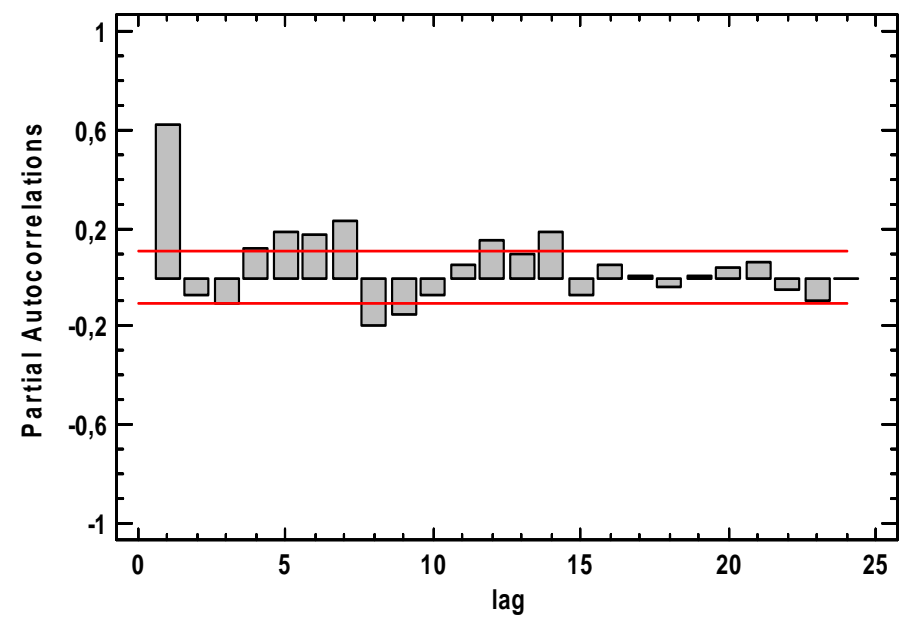


Grafik 3 'te kısmi otokorelasyonlar incelendiğinde dizide özellikle 0. Gecikmeden (lag)' ten itibaren anlamlı bir düşüş beklenirken bu durum oluşmamış, güven aralığının dışına çıkan değerler gözlenmektedir. Buradan hareketle, gerek otokorelasyon, gerekse kısmi otokorelasyon grafikleri, serinin durağanlaştırılması gerektiğini göstermektedir. Bu nedenle, seriyi durağanlaştırmak için 1.derece farkı alınmaktadır. Durağanlaştırılmış seri üzerinde model denemeleri yapılmaktadır.

Yapılan denemeler sonucunda uygun modelin ARIMA $(2,1,1)$ olduğu tespit edilmektedir. Diğer tüm uygun model sınamaları ve hata terim katsayılarına ilişkin değerler Ek $\sigma^{\prime}$ dedir. Ek 6 incelendiğinde AIC (Akaike Information Criterion) değerine göre en uygun model ARIMA $(2,1,1)^{\prime}$ dir. Çünkü en düşük AIC değeri ARIMA $(2,1,1)$ modeline aittir. Uygun modelin \%95 güven aralığında uygunluğu, Grafik 4' te özetlenmektedir.

\section{Grafik 4: ARIMA $(2,1,1)$ modeli için Zaman Serisi Grafiği}

Time Sequence Plot for Gunluk Satis $\operatorname{ARIMA}(2,1,1)$

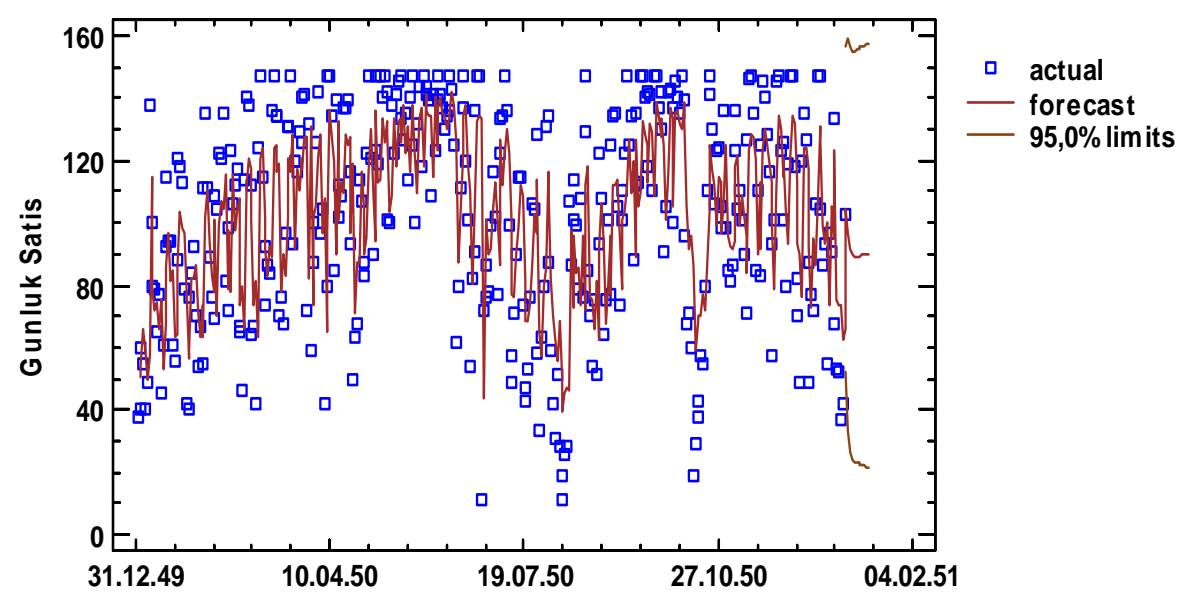

Grafik 4' te görülebileceği gibi model gerçekleşen değerlerin dağılımını önemli ölçüde (\%95) açıklamaktadır. Test istatistikleri Tablo 2' de özetlenmektedir.

Tablo 2 sonuçları incelendiğinde t-istatistiği değerleri (10.6792, -2.54103, 42.4504) \%95 güven aralığında anlamlıdır. Böylelikle bu model, KDS' de ana üretim/hizmet çizelgesinin belirlenmesinde kullanılabilir bir öngörü aracı olarak kabul edilmektedir. 


\section{SONUÇ}

Otel işletmelerinde yönetimsel ve operasyonel açıdan işlerin doğru ve kesintisiz olarak yapılarak müşteri memnuniyetinin en üst düzeye çıkarılması önemlidir. Bu amacı gerçekleştirilebilmek için talebin bilinmesi ya da doğru tahmin edilmesi önemli bir nokta olmaktadır. Bu nedenle oda talebinin öngörülmesinde temel modellerden biri olan ARIMA modeli kullanılarak otel işletmelerine yardımcı olmak hedeflenmektedir.

$\mathrm{Bu}$ amaçla yapılan çalışmada ARIMA $(2,1,1)$ modeline ulaşılmıştır. Modele ait test istatistikleri \%95 güven aralığında; $A R(1)$ için $p=0, A R(2)$ için $p=0.01$ ve $M A(1)$ için $p=0$ 'dır. Modelin uygunluğuna AIC (Akaike Information Criterion) kriterine göre karar verilmiştir. Analizlerde StatGraphics 16.2 ve Eviews 8 kullanılmıştır.

Parametreleri belirlenmiş model C \#' ta kodlanmıştır. Bu kodlar, otellerin malzeme ihtiyaç planlamasını yapan bir KDS'ye girdi oluşturmakta; model tabanında yer almaktadır. ARIMA modelinin rassal süreçleri modellemedeki başarısı ve kısa dönemlerdeki performansı göz önünde bulundurulduğunda, otel işletmelerinin oda talebinin öngörülmesinde uygun bir model ve işletmelerin gelecek ile ilgili planlamalarına yardımcı olacağı düşünülmektedir.

Çalışma sonucu geliştirilen model, KDS'de oda talebi için ana hizmet çizelgesinin oluşturulmasında kullanılmaktadır. Bu ana çizelge otellerde malzeme ihtiyaç planlamasında kullanılmaktadır. Bu çizelge doğru zamanda, doğru miktarda ve türde malzemenin doğru yerde bulundurulmasını, işlerin zamanında yapılmasını ve maliyetlerde düşüşü sağlamaktadır.

\section{KAYNAKÇA}

Box, G.E.P., Jenkins, G.M. and Reinsel, G.C. (2008), Time Series Analysis: Forecasting and Control, Hoboken, N.J.: Wiley, p. 305-307

Burger, C.J.S.C., Dohnal,M., Kathrada,M. and Law, R. (2001), A Practitioners Guide to Time Series Methods For Tourism Demand Forecasting-A Case Study Of Durban, South Africa, Tourism Management, Volume 22, p. 403409

Chatfield, C. (2001), Time Series Forecasting, Boca Raton: Chapman\&Hall

Chen, R.J.C., Bloomfiled, P. and Cubbage, F.W. (2008), Comparing Forecasting Models İn Tourism, Journal of Hospitality\&Tourism Research, Volume 32, p. 3-21

Chen, K. and Wang, C.H. (2007), Support Vector Regression with Genetic Algorithms in Forecasting Tourism Demand, Tourism Management, Volume 28, p. 215-226

Cho, V. (2001), Tourism Forecasting and its Relationship with Leading Economic Indicators, Journal of Hospitality and Tourism Research, Volume 25, p. 399-420

Cho,V. (2003), A Comparison of Three Different Approaches to Tourist Arrival Forecasting, Tourism Management, Volume 24, p. 323-330

Chu, F. L. (2009), Forecasting Tourism Demand with ARIMA-Based Methods, Tourism Management, Volume 30, p. $740-751$

Chu, F. L. (1998), Forecasting Tourism Demand in Asian Pasific Countries, Annals of Tourism Research, Volume 25 , p. $597-615$

Dharmaratne, G. (1998), Forecasting Tourist Arrivals in Barbados, Annals of Tourism Research, Volume 22, p. 804-818 
Goh, C. and Law, R. (2002), Modelling and Forecasting Tourism Demand for Arrivals with Stochastic Nonstationary Seasonality and Intervention. Tourism Management, Volume 23, p. 499-510

Gooijer, J. G.D. and Hyndman, R.J. (2006), 25 Years of Time Series Forecasting, Volume 22, p. 443-473.

Kulendran, N. and Shan,J. (2002), Forecasting China's Monthly Inbound Travel Demand, Journal of Travel \&Tourism Marketing, Volume 13, p.5-19

Kulendran, N. and Witt, S.F. (2003), Leading Indicator Tourism Forecasts, Tourism Management, Volume 24, p. 503-510

Lim,C. and McAleer, M. (2002), Time Series Forecasts of International Travel Demand for Australia

Lim, C. and Pan, G.W. (2005), Inbound Tourism Developments and Patterns in China, Mathematics and Computers in Simulation, Volume 68, p. 499-507

Madsen,H. (2008), Time Series Analysis, Boca Raton: Chapman\&Hall

Makridakis, S., Hibon, M. (1979), Accuracy of Forecasting: an Empirical Investigation. Journal of the Royal Statistical Society, Series A General, Volume 142, 97-145

Montgomery, D.C., Jennings, C.L. and Kulahci, M. (2008), Introduction to Time Series Analysis and Forecasting, Hoboken, N.J.: Wiley Interscience, 405-409

Nahmias, S. (2009), Production and Operation Analysis, Singapore: McGraw Hill, 94-95

Preez, J.D. and Witt, S. F. (2003), Univariate Versus Multivariate Time Series Forecasting an Application to International Tourism Demand, International Journal of Forecasting, Volume 19, 435-451

Rajopadhye, M., Ghalia, M.B., Wang, P.P., Baker, T. and Eister, C.V. (2001), Forecasting Uncertain Hotel Room Demand, Information Sciences, Volume 132,1-11

Sevüktekin, M. and Nargeleçekenler, M. (2010), Ekonometrik Zaman Serileri Analizi, Nobel Dağııım, İstanbul

Song, H.,Witt, S.F. and Jensen,T.C. (2003), Tourism Forecasting: Accuracy of Alternative Econometric Models. International Journal of Forecasting, Volume 19, 123-141

Witt, S.E. and Witt, C.A. (1995), Forecasting Tourism Demand: A Review of Empirical Research, International Journal of Forecasting, Volume 11, 447-475

Wong, K.K.F., Song, H., Witt, S.F. and Wu, D.C. (2007), Tourism Forecasting: to Combine or not to Combine? Tourism Management, Volume 28, 1068-1078

Yule, G. U. (1927), On a Method of Investigating Periodicities in Disturbed Series, with Special Reference to Wolfer's Sunspot Numbers, Philosophical Transactions of the Royal Society London Series A, Volume 226, 267298

Yüksel, A. (2007), An Integrated Forecasting Approach to Hotel Demand, Mathematical and Computer Modelling, Volume 46, 1063-1070

http://www2.unwto.org/content/data-0 Erişim Tarihi: 24.05.2015 